\title{
Zersetzung der Oele in den ölhaltigen Samen.
}

Pelouze und Boudet hatten schon vor 17 Jahren gefunden, dass das käufliche Palmöl ein Gemenge ist aus neutralem Oel, Oelsüss und fetten Säuren, deren Menge zuweilen $4 / 5$ des ganzen Oels betrug. Die Zersetzung anderer fetten Oele in den ölführenden Samen durch die Einwirkung der eiweissartigen Körper derselben, machte Pel ou z e neuerdings zum Gegenstande einer Untersuchung, aus welcher wir nachstehende Resultate hervorheben.

Wenn Oelsamen zerrieben aufbewahrt werden, geht das anfangs darin vorhandene neutrale Oel nach und nach in fette Säuren und Oelsüss über. Leinsamen, Raps, Senf, blauer und weisser Mohn, Erdnuss (Arachis hypogaea), Sesam, Leindotter, Wallnüsse, Haselnüsse, süsse und bittere Mandeln gaben frisch zerrieben und unmittelbar darauf ausgepresst oder vermittelst Aether oder Benzin ausgezogen ein neutrales, völlig säurefreies Oel. Dieselben Oelsamen, fein zerrieben in Mengen von 2-6 Kilogrammen in vollgefüllten, mit Korkstöpseln verschlossenen Steinzeuggefässen einige Tage aufbewahrt, enthielten ziemliche Mengen von Oelstiss und fetten Säuren, die sich nach mehrmonatlichem Aufbewahren beträchtlich vermehrten. So gaben zerriebene Wallnusskerne bei $10-25^{\circ} \mathrm{C}$. fünf Tage lang in verschlossenen Gefässen aufbewahrt ein Oel, worin 9 Proc. fette Säuren; eine andere Probe nach achttägigem Aufbewahren ein Oel, worin 15 Proc. fette Säuren enthalten waren. Sesamöl, aus 6 Tage lang aufbewahrten zerriebenen Samen, enthielt 6 Proc., nach einem Monat der Aufbewahrung gepresst 17,5 Proc. und nach drei Monaten 47,5 Proc. fette Säuren. Zerriebene süsse Mandeln, nach drei Wochen gepresst, gaben ein Oel, worin $31 / 2$ Proc. fette Säuren; Erdnüsse, nach einem Monat ein Oel, worin 6,3 Proc., nach drei Monaten ein solches mit 14 Proc. fetten Säuren. Zerriebener Leinsamen und Raps lieferten nach drei Wochen der Aufbewahrung ein Oel mit 5 bis 6 Proc. fetten Säuren. Die freiwillige Spaltung der neutralen Oele in fette Säuren und Glycerin hängt nicht allein von der Temperatur ab, bei welcher dieselben mit den übrigen Bestandtheilen der ölführenden Samen zusammentreffen, sondern auch von der grösseren oder geringeren Menge der zerriebenen Samen, mit denen man die Versuche anstellt. Immer bleibt noch eine gewisse Menge des Oels unzersetzt.

Unter allen Oelen zersetzt sich das Mohnöl am 
schnellsten; nach viermonatlicher Aufbewahrung des zerriebenen Mohnsamens in verschlossenen, damit angefüllten Gefässen lieferte derselbe ein Oel, welches 85-90 Proc. fette Säuren enthielt.

Die Oelkuchen enthalten immer fette Säuren, die alten nur solche allein und kein unverändertes neutrales Oel mehr. Im Mittel sind 10 Proc. Oel in den käuflichen Oelkuchen anzunehmen.

Mit Wasser benetzt gehen sie nach einigen Tagen in stinkende ammoniakalische Fäulniss über, enthalten dann aber weniger fette Säuren als die zerriebenen unbenetzt aufbewahrten Oelkuchen; der Grund liegt wohl in der Zerstörung des Ferments durch die Fäulniss.

Die Wallnuisse, Haselnüsse, die süssen und bitteren Mandeln enthalten beträchtliche Mengen von Zucker und zwar nur gemeinen Zucker, keine Spur von Krümelzucker. Die Menge desselben in den süssen Mandeln beträgt 10 Proc., in den Wallnüssen $121_{2}$ Proc. und in den Haselnüssen 15 Proc.

Pelouze sagt nicht, wie er die Menge der fetten Säuren in den Oelsamen und fetten Oelen bestimmte; nur so viel bemerkt er, dass er sich nicht auf das blosse Ausziehen der fetten Säuren mit Alkohol beschränkt habe, weil er gefunden, dass durch Vermittelung der fetten Säuren die neutralen Oele sich in grösserer Menge im Alkohol lösten.

Die Verseifung fetter Oele durch Kali- und Natronlauge geht nach Pelouze nur wegen unvollkommener Berïhrung der auf einander wirkenden Körper so langsam vor sich. Löse man ein neutrales Oel in heissem Alkohol und füge eine alkoholische Kalihydratlösung hinzu, so werde das Oel augenblicklich verseift und Wasser scheide keine Spur von fettem Oel aus dieser Lösung.

Auch beim Mischen fetter Oele mit überschüssiger concentrirter Schwefelsäure geschah augenblicklich eine Zerlegung der Oele unter Bildung von gepaarten Verbindungen der Schwefelsäure mit den fetten Säuren, so wie der Schwefelsäure mit dem Oelsüss.

Die Rückstände von der Reinigung des Rüböls durch Schwefelsäure nach Thénard's Methode, bestehen vorzüglich aus den genannten gepaarten Schwefelsäuren. Diese Rückstände werden in den Rübenbranntweinbrennereien zur Verhütung des Schïumens den gährenden Mischungen in kleinen Mengen zugesetzt.

Die angeführten Beobachtungen von $\mathrm{Pel}$ ouze sind 
von praktischer Bedeutung. So enthält Leinsamenmehl, je nach seinem Alter, mehr oder weniger fette Säuren und muss deshalb als Arzneimittel angewandt, verschiedene Wirkungen zeigen; es sollte deshalb nur möglichst frisch bereitet angewendet werden.

Eine Mandelmilch, die im frischbereiteten Zustande nur neutrales Siissmandelöl enthält, wird bei eintägiger Aufbewahrung schon einen Theil seines Oels in fette Säure verwandelt besitzen.

Die Speiseöle werden einen angenehmen oder unangenehmen Geschmack besitzen, je nachdem man sie durch Pressen frisch zerriebener oder vor kürzerer oder längerer Zeit zerriebener Oelsamen bereitete. Die besten, wohlschmeckendsten Oele liefern die unmittelbar vor dem Auspressen zerriebenen Samen. (J. Pelouze, Ann. de Chim. et de Phys. 3. Sér. Novbr. 1855. Tome XLV. p. 319-327.)

Dr. H. Ludwig.

\section{Die Hypogäsăure, eine neue Fettsẳure.}

Ausser der Arachinsäure, welche Gössmann in dem Erdnussöl früher fand, haben Gössmann und Scheven in demselben Oel noch eine andere fette Säure aus der Reihe der Oelsäure $\mathrm{C}^{n} \mathrm{H}^{n-2} \mathrm{O}^{4}$ gefunden, welche sie Hypogäsäure nennen. Man erhält sie aus dem verseiften Oel durch Zersetzung der Seife, mehrmaliges Umschmelzen der Säuren in Wasser, Lösen in Alkohol, Fällen der Lösung mit essigsaurer Magnesia und Arnmoniak und Hinstellen des Filtrats, nachdem es mit überschüssiger Bleizuckerlösung und Ammoniak versetzt ist. Wenn sich nichts mehr ausgeschieden, wird der Niederschlag gepresst und mit Aether völlig erschöpft. Die ätherische Lösung des Bleisalzes wird bei möglichstem Luftabschluss durch verdünnte Salzsäure zerlegt, das Chlorblei abfiltrirt und das Filtrat mit ausgekochtem Wasser geschüttelt. Die obenauf schwimmende ätherische Lösung der Säure, von dem grösseren Theile des Aethers durch Destillation befreit, setzt bei niedriger Temperatur gelbliche Krystalle ab, die durch Umkrystallisiren aus Alkohol weiss und nadelförmig werden. In der Lösung bleibt eine gelbliche, wahrscheinlich durch Oxydation veränderte Säure, die aber auch in niedriger Temperatur zu gelblichen, sternförmig gruppirten Nadeln erstarrt, und durch Umkrystallisiren aus Alkohol sich rein erhalten lässt.

Die reine Säure besteht aus nadelförmigen Aggre- 